\title{
Miosite relacionada ao vírus da dengue
}

\author{
Miosytis related to dengue vírus
}

\section{Paloma Feitosa Pinho Gomes ${ }^{1}$, Laila Morais Nahass Franco ${ }^{1}$, Géssyka Soares Castro ${ }^{1}$, Neuza Helena de Paula Melo², Talitha Araújo Faria²}

Gomes PFP, Franco LMN, Castro GS, Melo NHP, Faria, TA. Miosite relacionada ao vírus da dengue / Miosytis related to dengue vírus. Rev Med (São Paulo). 2018 maio-jun.;97(3):353-6.

\begin{abstract}
RESUMO: A dengue é uma doença infecciosa viral causada por um arbovírus, havendo quatro sorotipos virais diferentes, todos relacionados com dengue clássica, podendo causar várias formas clínicas. No Brasil, desde 2010, existem os quatro sorotipos circulando. A mialgia é uma queixa recorrente na doença, mas raramente são descritos quadros de miosite. Esta, quando ocorre, afeta principalmente os membros inferiores culminando com a diminuição ou até a incapacitação transitória do deambular, o que ocasiona a busca por atendimento médico. O objetivo do presente estudo é relatar sobre a miosite viral como manifestação da dengue em dois casos ocorridos no mesmo período em Paracatu-MG.
\end{abstract}

Descritores: Dengue; Miosite/virologia; Mialgia; Caminhada.

\begin{abstract}
Dengue is a viral infeccious disease caused by arbovirus. There are four different kinds of serotype virus, all of them related with the classical dengue and they can cause plenty of clinical ways. In the Brazil, since 2010, there are all four serotypes flowing around. The myalgia is a recurrent complaint of the disease, but clinical condition of miosytis rarely described. When it happens, it mainly affects the lower members culminating with the decrease or even with the temporary incapacitation of the wander, which takes to the medical care. The goal of this study is to report about the viral myositis as a dengue sign in two cases that happened at the same time in Paracatu-MG.
\end{abstract}

Keywords: Dengue; Myositis/virology; Myalgia; Walking.

Trabalho apresentado no $19^{\circ}$ Congresso Brasileiro de Infectologia Pediátrica, Fortaleza, CE, 2-5 nov. 2016; $2^{\circ}$ Congresso Acadêmico de Medicina e Saúde, Paracatu, MG, 18-20 ago. 2017.

1. Faculdade Atenas, Paracatu, MG, BR. Acadêmico de Medicina. ORCID: Gomes PFP - https://orcid.org/0000-0002-8485-1886; Franco LMN - https://orcid.org/0000-0002-0404-6909; Castro GS - https://orcid.org/0000-0002-2094-6640. Email: paloma-pinho@hotmail. com; lailamnahass@gmail.com; gessyka_15_sjp@hotmail.com.

2. Faculdade Atenas, Paracatu, MG, BR. Professora do Departamento de Pediatria, Orientadora. ORCID: https://orcid.org/0000-00030963-5806. E-mail: nadimar16@terra.com.br.

3. Faculdade Atenas, Paracatu, MG, BR. Professora de Pensamento Científico, Orientadora. ORCID: https://orcid.org/0000-0002-42526794. E-mail: talithabio@yahoo.com.br.

Endereço para correspondência: Paloma F. P. Gomes. Rua Geraldo Alves Correa, 232, Apt. 2. Bairro Juscelino Kubitscheck. Paracatu, MG, BR. 


\section{INTRODUÇÃO}

A dengue é uma doença infecciosa viral causada da uor um arbovírus do gênero Flavivírus e
da família Flaviviridae, possui quatro sorotipos virais diferentes: DEN-1, DEN-2, DEN-3 e DEN-4, sendo que qualquer um dos quatro sorotipos podem levar a dengue clássica e ainda podem causar as formas graves da doença; entretanto os sorotipos 2 e 3 estão mais relacionados aos casos graves e fatais. É transmitida por fêmeas de mosquitos hematófagos do gênero Aedes, no qual o Aedes Aegypty é o principal vetor nas aéreas urbanas ${ }^{1,2}$.

De acordo com o Ministério de Saúde foram registrados 802.429 casos prováveis de dengue no período de janeiro a abril de 2016. Sendo que a região Sudeste teve a maior taxa de incidência, com $57,8 \%$ dos casos prováveis ${ }^{3}$.

A dengue atualmente é considerada um dos principais problemas de saúde publica no Brasil em decorrência da sua alta incidência e da sazonalidade favorável do país para a multiplicação do seu vetor, além disso, a doença incapacita temporariamente as pessoas de suas atividades diárias. É importante um assíduo monitoramento dos novos sorotipos ou genótipos que chegam ao Brasil, que predispõe um possível aumento da virulência do agente ${ }^{4}$.

A dengue se manifesta com um quadro clínico semelhante a outras doenças febris agudas. Na sua forma clássica se manifesta com febre, cefaléia, dor retroorbitária, prostração, artralgia, mialgia e rash maculopapular; na sua forma mais grave de febre hemorrágica da dengue apresenta dor abdominal intensa, vômitos, lipotímia, hemorragias importante, diminuição da diurese e outros sinais de hipotensão. Ainda pode apresentar outras manifestações raras que acometem o $\mathrm{SNC}$, rins e fígado ${ }^{2}$.

Atualmente tem aumentado casos de miosite viral relacionados à dengue na área pediátrica, uma manifestação rara, porém tem se notado o aumento do número de casos, o quadro é marcado com dor de início súbito na panturrilha acompanhada de dificuldade para deambular, ainda não se sabe a fisiopatologia, mas alguns autores relacionam como uma manifestação neurológica acompanhada de déficit motor e outros autores acreditam que ocorra dano muscular por processos mediados imunologicamente ou que partículas virais invadam os músculos causando danos. A miosite viral é um quadro passageiro com resolução espontânea de 48 a 72horas, entretanto poucos sabem sobre sua evolução. Com isso os pais acabam procurando unidades de pronto socorro com grande preocupação devido à incapacidade repentina de seus filhos deambularem ${ }^{5,6}$.

O objetivo do presente trabalho é relatar sobre a miosite viral como manifestação da dengue através dos achados clínicos e laboratoriais.

\section{RELATOS DE CASOS}

\section{Caso 1}

E.O.C, sexo masculino, cor parda, quatro anos de idade, procurou hospital particular com queixa de febre elevada $\left(39^{\circ} \mathrm{C}\right)$ há três dias e queda do estado geral. Associado ao quadro, na madrugada do dia do atendimento, o menor apresentou dor intensa em ambas as panturrilhas com dificuldade para se manter em pé, impedindo a deambulação. Estava fazendo uso de AINES. O paciente foi encaminhado ao Pronto Socorro do Hospital Municipal de Paracatu, com suspeita de síndrome de Guillain Barré segundo avaliação do neurologista.

Ao exame físico na unidade referida, o paciente apresentava-se em regular estado geral, prostrado, hipoativo, febril $\left(38,3^{\circ} \mathrm{C}\right)$, hidratado, corado. Com peso de $20 \mathrm{Kg}$. Otoscopia apresentando rolha de cerúmen bilateralmente, não permitindo visualização da membrana timpânica e oroscopia sem alterações. A ausculta cardiopulmonar normal. Abdome plano, flácido, indolor à palpação, sem massas ou visceromegalias palpáveis. As eliminações fisiológicas encontravam-se sem alterações. Presença de dor severa a palpação de ambas as panturrilhas, limitação da dorsoflexão e diminuição do reflexo patelar e Aquileu bilateralmente. Os demais grupos musculares não foram afetados.

Os exames laboratoriais realizados no dia da internação demonstraram: hemácias: $4.100 .000 / \mathrm{mm}^{3}$; hemoglobina (Hg): 12,6 g/dl; hematócrito $(\mathrm{Ht}): 38,0 \%$; V.C.M: 92,68 um³; H.C.M: 30,73 pg; C.H.C.M: 33,16 g/ $\mathrm{dl}$; Leucócitos totais: $4.000 / \mathrm{mm}^{3}$ com $3 \%$ de eosinófilos, $0 \%$ de bastões, $40 \%$ de segmentados, $52 \%$ de linfócitos, $5 \%$ de monócitos e plaquetas: $168.000 / \mathrm{mm}^{3}$; velocidade de hemossedimentação (VHS): $10 \mathrm{~mm}$; proteína $\mathrm{C}$ reativa: positivo $6 \mathrm{mg} / \mathrm{l}$; ureia: $30,0 \mathrm{mg} / \mathrm{dl}$; creatinina: 0,58 mg/dl; sódio: 139,0 $\mathrm{mEq} / \mathrm{L}$; potássio: 4,9 mEq/L; cálcio total: $10,5 \mathrm{mg} / \mathrm{dl}$; magnésio: $2,30 \mathrm{mg} / \mathrm{dl}$; EAS sem alterações;creatinofosfoquinase (CPK): $1.730 \mathrm{U} / \mathrm{L}$ (referencia laboratorial:26 a $189 \mathrm{U} / \mathrm{L}$ ); creatinofosfoquinase MB (CKMB): $52 \mathrm{U} / \mathrm{L}$ (referencia laboratorial: até $25 \mathrm{U} / \mathrm{L}$ ).

Devido ao quadro, o paciente foi internado para realização de hidratação venosa, analgesia e repouso, sendo solicitada uma segunda avaliação do neurologista. No $2^{\circ}$ dia de internação hospitalar, durante consulta neurológica, o paciente não apresentou as alterações do quadro anterior, inclusive voltando a deambular. No $3^{\circ}$ dia de internação, $6^{\circ}$ dia da doença, paciente apresentava-se afebril, deambulando, sem dores em panturrilhas. Recebeu alta hospitalar, mantendo analgesia se necessário e hidratação oral. Durante a internação, foi solicitado o teste rápido para detecção qualitativa de antígeno NS1 para o vírus da Dengue, método imunocromatográfico, com resultado reativo.

Um dia após a alta, em consulta particular com pediatra, o paciente persistia afebril, apresentando exantema associado a prurido em MMSS e MMII. Os 
novos exames mostraram: hemácias: 4,50 milhões/ $\mathrm{mm}^{3}$; hemoglobina $(\mathrm{Hg}): 12,0 \mathrm{~g} / \mathrm{dl}$; hematócrito $(\mathrm{Ht})$ : 36,0\%; V.C.M: 80 fL; H.C.M: 26,7pg; C.H.C.M: 33,3\%; Leucócitos totais: 7.500 cels. $/ \mathrm{mm}^{3}$ com $3 \%$ de eosinófilos, $0 \%$ de bastões, $39 \%$ de segmentados, $55 \%$ de linfócitos, 3\% de monócitos e plaquetas: 338.000/ $\mathrm{mm}^{3}$; velocidade de hemossedimentação (VHS): 15 mm; EAS sem alterações; Transaminase glutâmico oxalacética (TGO): $34 \mathrm{U} / \mathrm{L}$ (referência laboratorial: 10 a 60 u/L); Transaminase glutâmico pirúvica (TGP): 12 U/L (referência laboratorial: 10 a 60 u/L); creatinofosfoquinase (CPK): 103,0 U/L (referência laboratorial: 32 a 294 U/L); creatinofosfoquinase $\mathrm{MB}(\mathrm{CKMB}): 1,5 \mathrm{ng} / \mathrm{mL}$ (referência laboratorial: até $5 \mathrm{ng} / \mathrm{mL}$ ). O teste sorológico para Dengue, método Imunocromatográfico, demonstrou anticorpos anti dengue IgG positivo e anticorpos anti dengue IgM positivo. No $18^{\circ}$ dia da doença, ao ser novamente reavaliado, o paciente estava assintomático e curado da doença.

\section{Caso 2}

G.R.S, sexo masculino, cor pardo, oito anos de idade, procurou o Hospital Municipal de Paracatu (HMP) com queixa de febre alta, vômitos e dor abdominal. Permaneceu em observação fazendo uso de dipirona endovenoso com melhora dos sintomas. Após 24 horas de internação recebeu alta.

No dia seguinte, pela manhã, retornou ao HMP com quadro de dor intensa em ambas as panturrilhas impedindo a deambulação. Os exames laboratoriais solicitados mostraram: hemácias: 4,46 milhões $/ \mathrm{mm}^{3}$; hemoglobina (Hg): 12,0 g/dl; hematócrito (Ht): 36,0\%; V.C.M: 80,7 fL; H.C.M: 26,9 pg; C.H.C.M: 33,3\%; Leucócitos totais: $5.200 / \mathrm{mm}^{3}$ com $3 \%$ de eosinófilos, $0 \%$ de bastões, $30 \%$ de segmentados, $56 \%$ de linfócitos, $11 \%$ de monócitos e plaquetas: $61.000 / \mathrm{mm}^{3}$; colesterol total: $150 \mathrm{mg} / \mathrm{dL}$; triglicérideos: $146 \mathrm{mg} / \mathrm{dL}$; LDL: $73 \mathrm{mg} / \mathrm{dL}$; VLDL: 29mg/ dL; HDL: 48mg/dL; glicose: $99 \mathrm{mg} / \mathrm{dL}$; ureia: 26,0 mg/dl; creatinina: $0,6 \mathrm{mg} / \mathrm{dl}$; sódio: $136,0 \mathrm{mEq} / \mathrm{L}$; potássio: 4,0 $\mathrm{mEq} / \mathrm{L}$; cálcio total: $10,4 \mathrm{mg} / \mathrm{dl}$; magnésio: $2,50 \mathrm{mg} / \mathrm{dl}$; EAS sem alterações; creatinofosfoquinase (CPK): 3540,0 U/L (normal até 294,0 U/L); Lactato Desidrogenase (LDH): 634,0 U/L (normal até 300,0 U/L). O teste sorológico para Dengue, método Imunocromatográfico, demonstrou anticorpos anti dengue IgG positivo e anticorpos anti dengue IgM positivo.

A criança recebeu alta hospitalar no mesmo dia, mantendo acompanhamento ambulatorial por pediatra em consultório particular. Novos exames realizados demonstraram: glicose $51 \mathrm{mg} / \mathrm{dL}$; creatinofosfoquinase (CPK): 224,0 U/L (normal até 294,0 U/L); Lactato Desidrogenase (LDH): 471,0 U/L (normal até 300,0 U/L). Quinze dias após a internação, foi novamente reavaliada, estando assintomática, em bom estado geral, com peso $32,5 \mathrm{~kg}$, estatura de $1,36 \mathrm{~m}$, frequência cardíaca de $100 \mathrm{bpm}$, frequência respiratória 12 ipm, PA de 100x60 mmHg, sem alterações em demais sistemas. Logo, o paciente evoluiu para a cura completa da doença.

\section{DISCUSSÃO}

Nos casos estudados, ambas as crianças têm idade pré-escolar e apresentaram febre por três dias (média de $38,5^{\circ} \mathrm{C}$ ), acompanhado de hiporexia, incapacidade de deambular no terceiro dia do quadro e presença de eritema após 7 dias do início dos sintomas no paciente do caso 1 , sendo que o caso 2 não apresentou eritema. Coincidindo com os relatos literários, na dengue em sua forma clássica os pacientes apresentam febre geralmente de início súbito, podendo chegar a $40^{\circ} \mathrm{C}$, que na maioria das vezes mantémse por três dias, mas pode permanecer até o sexto ou oitavo dia, ou ainda ser bifásica. Dores no corpo, artralgia e mialgia, especialmente disseminada na região lombar e membros inferiores, acompanham o estado febril. Cefaleia retro-orbitária, náuseas, disgesia, anorexia podem estar presentes. Pode ocorrer erupção cutânea no início, com eritema generalizado e fugaz. Após três a quatro dias o exantema maculopapular fica mais evidente na face, tronco, membros e também nas extremidades, principalmente nas regiões palmo plantares, com sensação de queimação ${ }^{3,6,7}$.

Em crianças, na maioria das vezes, se apresenta como uma síndrome febril com sinais e sintomas inespecíficos, como apatia ou sonolência, recusa de alimentação, vômitos, diarréia ou fezes amolecidas ${ }^{8}$.

O paciente do Caso 1 apresentou no exame físico além da incapacitação de deambular, prostração, paralisia de membros inferiores, hiporreflexia patelar e aquileu, dor à palpação da panturrilha bilateral, limitação da dorsoflexão, nuca livre sem sinais de irritações meníngeas. Neste dia a suspeita pelo neurologista foi de Síndrome de Guillan- Barré (SGB), uma vez que existem relatos desta pós-dengue.

Em seu estudo, Orsini et al. ${ }^{9}$ evidencia que a recuperação é difícil e o prognóstico não é bom quando se trata de SGB. ${ }^{9}$ O paciente referido, no quarto dia evoluiu com diminuição da dor em panturrilhas, foi reavaliado e apresentou melhora do quadro, voltando a deambular. Foi descartado a possibilidade de SGB, uma vez que teve uma rápida recuperação e aumento da creatinofosfoquinase, não sendo necessária a coleta do líquor.

No Caso 2, o paciente também teve incapacitação de deambular, com recuperação rápida desta. Aumento da creatinofosfoquinase e LDH foram evidenciados nos exames laboratoriais. Estudos demonstram que se observa no exame hematológico leucopenia com linfocitopenia, e plaquetopenia, além de aumento das aminotrasnferase ${ }^{10}$.

O diagnóstico de ambos os casos foi miosite viral associada ao vírus da dengue, e se tratando de diagnósticos diferenciais tem-se a rabdomiólise, SGB, dermatomiosite juvenil e distrofia muscular hereditária ${ }^{11}$. A elevação da 
CPK é o exame laboratorial mais específico. Assim como nos estudos de Garcia ${ }^{6}$ e Fernandes et al. ${ }^{11}$, nos casos a cima esta enzima estava aumentada. No entanto, é necessário excluir rabdomiólise com o exame de urina, que cursaria com mioglobunúria, no presente estudo foi realizado e não houve o aumento desta.

Os pacientes estudados eram do sexo masculino, indo de encontro ao que foi relatado por $\mathrm{Garcia}^{6} \mathrm{e}$ Fernandes et al. ${ }^{11}$, que referem essa patologia em maior quantidade nesse sexo. Porém, na análise desses autores, os pré-escolares não tiveram alteração nos reflexos e força muscular. Na presente pesquisa, ambas crianças cursaram com hiporreflexia, diminuição do tônus e força muscular. Tais alterações sugerem a diversidade clínica que a miopatia pelo vírus da dengue pode apresentar e um possível acometimento do SNC que pode estar associado.

A abordagem terapêutica inicial foi feita com dipirona e ibuprofeno, além de oferta hídrica abundante, uma vez que não suspeitou inicialmente de dengue, mas sim de um quadro de influenza. Mantiveram em internação hospitalar por dois dias, porém com a involução de todos os sintomas e melhora total do quadro geral, receberam alta. Na reavaliação após média de 15 dias, novos exames foram solicitados com a normalização da CPK, IGM e IGG positivos para dengue. Tal evolução da doença tem compatibilidade com todos trabalhos publicados que relacionam miosite ao vírus da dengue $e^{6,10,11}$.

Portanto, em Paracatu em um curto período surgiram 2 casos idênticos confirmados de miopatia associada ao vírus da dengue, o que sugere a necessidade de novos estudos para investigação e alerta dos profissionais de saúde para esta possibilidade.

\section{REFERÊNCIAS}

1. Dalbem AG, Herling JD, Vieira RG, Souza VAI. Dengue clássica e febre hemorrágica da dengue: etiologia, fisiologia, epidemiologia e fatores de risco. Rev Ciên Estud Acad Med (Cáceres). 2014;1(1):18-36. Disponível em: https://periodicos. unemat.br/index.php/revistamedicina/article/view/60/48.

2. Santos MS. Incidência da dengue em uma comunidade urbana de Salvador, Bahia: um estudo prospectivo de coorte [Monografia]. Salvador, BA: Faculdade de Medicina da Bahia, Universidade Federal da Bahia; 2014. Disponível em: http:// repositorio.ufba.br/ri/handle/ri/16108.
3. Brasil. Ministério da Saúde. Secretaria de Vigilância em Saúde. Boletim Epidemiológico. Monitoramento dos casos de dengue, febre de Chikungunya e febre pelo vírus Zika até a Semana Epidemiológica 13, 2016. Bol Epidemiol. 2016;47(18):1-10. Disponível em: http://portalarquivos2.saude.gov.br/images/ pdf/2016/abril/26/2016-014---Dengue-SE13-prelo.pdf.

4. Valadares AF, Rodrigues C. Filho J, Peluzio JC. Impacto da dengue em duas principais cidades do Estado do Tocantins: infestação e fator ambiental (2000 a 2010). Epidemiol Serv Saude. 2013;22(1):59-66. doi: https://doi.org/10.5123/s167949742013000100006.

5. Cardin SP. Descrição clínica - epidemiológica de uma série de casos de miosite aguda viral [Dissertação]. Botucatu: Universidade Estadual Paulista, Faculdade de Medicina de Botucatu; 2010. doi: https://doi.org/10.5016/dt000620693.

6. Garcia EW. Relato de caso: miosite causada por vírus da dengue. RP Residência Pediatrica. 2015;5(1):36-9. Disponível em: http://residenciapediatrica.com.br/detalhes/138/relato-decaso--miosite-causada-por-virus-da-dengue.

7. Xavier AR, Freitas MS, Loureiro FM, Borghi DP, Kanaan S. Manifestações clínicas na dengue - diagnóstico laboratorial. Rev Bras Med. 2014;102(2):7-14. Disponível em: http://files. bvs.br/upload/S/0047-2077/2014/v102n2/a4189.pdf.

8. Sartori B, Morato M, Fernandes SO, Fossa AM. Caracterizando dengue em crianças no município de Piracicaba. In: $5^{\text {a }}$ Mostra Acadêmica UNIMEP, $5^{\circ}$ Simpósio de Ensino de Graduação: Educação Brasileira: Extinção ou Sustentabilidade na Universidade; Piracicaba, SP, 23-25 out. 2007. p.1-6. Disponível em: http://www.unimep.br/phpg/mostraacademica/ anais/5mostra/4/556.pdf.

9. Orsini M, Freitas MRG, Nascimento OJM, Catharino MAS, Mello MP, Reis CHM, Carvalho RW. Síndrome de Guillain-Barré pós-infecção por dengue: relato de caso. Rev Neurocienc. 2010;18(1):24-7. Disponível em: http://www. revistaneurociencias.com.br/edicoes/2010/RN1801/280\%20 relato $\% 20 \mathrm{de} \% 20$ caso.pdf.

10. Ahmad R, Abdul LAK, Abdul RS. Myalgia Cruris epidemica: an unusual presentation of dengue fever. Southeast Asian J Trop Med Public Health. 2007;38(6):1084-7.

11. Fernandes RCSC, Tucci CR, Brunelli PB. Uma incomum manifestação da dengue. Rev Cient Fac Med Campos. 2008;3(1):13-6. Disponível em: http://www.fmc.br/ojs/index. php/RCFMC/article/view/147/116.

Submetido em: 02.10.17

Aceito em: 15.02 .18 